of ceriain globulin molecules other than gammaglobulin which bind calcium more effectively than albumin. ${ }^{1}-$ We are, etc.,

R. B. PAYNE

A. J. LitTle

R. B. WILliams J. R. MILNER

Department of Chemical Pathology,

Leeds (St. James's) University Hospital,

Leeds

1 Pedersen, K. O., Scandinavian fournal of Clinical and Laboratory Investigation, 1972, 30, 321

Robertson, W. G., Clinica Chimica Acta, 1969

$24,149$.

anden, K. O., Scandinavian fournal of Clinical and Laboratory Investigation, 1970, 25. 223.

5 Danowski, T. S., et al., American fournal of Diseases of Children, 1957, 93,604

6 Jones, J. H., et al., Quarterly fournal of Cleveland

Medicine, 1967, 36, 301 .

\section{Surgery in Crohn's Disease}

SIR,-Your leading anticle (23 February, p. 295 ) is slightly misleading. The following comments are pertinent to the subject:

(1) The vast majority of surgeons in the U.S.A. favour resection rather than bypass. A short-circuit procedure is advocated only in cases of Crohn's disease of the duodenum or in the elderly, debilitated patient with a "burnt out" stenosing lesion.

(2) Controversy no longer rages over the optimum extent of excision. Most centres experienced with the disease do not advocate excision of enlarged lymph nodes. Conservative surgery is the rule.

(3) The surgeon should be warned of perianal disease associated with asymptomatic intra-abdominal Crohn's disease. In our experience at the University of Chicago Hospitals adequate treatment of perianal lesions should be accompanied by excision of the intra-abdominal disease.

(4) The recent recognition of occult obstructive uropathy complicating Crohn's disease $^{1}$ should now be an essential part of the evaluation of these patients. Adequate treatment includes intestinal resection and ureterolysis to achieve renal decompression. -I am, etc.

Department of Surgery,

University of Chica

Chicago, Illinois

A. R. MoossA

Block, G. E., Enker, W. E., and Kirsner, J. B., Annals of Surgery, 1973, 178, 322.

\section{Assessing the Safety of Comatose and} Postanaesthetic Patients

SIR,-I was interested to read the technique for assessing the safety of postanaesthetic patients described by Drs. A. W. Grogono and A. R. de C. Deacock (20 April, p. 174). I am sure that it will prove to be a valuable and much-needed aid, but one aspect of the procedure deters me from adopting it regularly. However gently one might apply the pressure to the chin and however successfully the patient might resist it, any attempt to throttle a patient soon after he has recovered consciousness must cause some alarm. I think I know a sign that is just as sensitive but causes no discomfort.

The patient is laid in a flat supine position with the head on a low pillow. The toes of one foot are grasped and the foot gently dorsi- and planti-flexed alternately, the heel being kept in firm contact with alternately, the heel being kept in firm contact with point of the chin will follow the movements of the forefoot. As the movement is transmitted by ligaments rather than by muscles, paralysis does not significantly affect it. If the patient is conscious the movement of the chin is greatly reduced or absent. It is possible to rock the head visibly and so move the chin in a fully conscious person by exaggerating the movement of the foot, but such movement of the chin is so much less and requires so much more force to be applied that the sign is an effective way to assess the level of consciousness of a patient recovering from an anaesthetic.

Sometimes a patient may aotively move his foot in response to the passive movements. Alternatively he may raise his head in puzzlement as to what is going on. Either reaction confirms the alentness of the patient.-I am, etc.,

E. N. S. FRY

\section{Diet and Colonic Cance}

SIR, - With reference to your leading article (2 March, p. 339) we agree that it would be of interest to know if the incidence of cancer of the large bowel is appreciably lower in vegetarians than in the rest of the population. At present it is estimated that there are between 100,000 and 500,000 vegetarians in Britain. For some years we have been studying the incidence of disease in vegetarians. The findings so far would indicate that there is no apparent difference in the incidence of cancer in general between vegetarians and the rest of the population.

Estimation of the incidence of cancer of the large bowel among vegetarians is no simple task. The average annual incidence of cancer of the large bowel among the general population is estimated to be in the region of $30-40$ per 100,000 . Thus the detection of any significant difference in its incidence between vegetarians and the rest of the population would require the study of a very large sample, possibly the total vegetarian population of the country. In practical terms this is very difficult. However, we are currently investigating the incidence of all cancers and other diseases of the alimentary tract in vegetarians and hope that this may throw some light on the matter.-We are, etc.

FrEY R. ELLIS THOMAS A. B. SANDERS

Kingston and Richmond Area Health Authority, Department of Pathology Kingston upon Thames, Surrey

\section{Self-administered Clinical Questionnaires} for Outpatients

SIR,-Drs. J. M. Gumpel and A. M. S. Mason (27 April, p. 209) have shown that standard items of information are obtained much more consistently by questionnaire than by conventional history taking. The information is also much more accessible since it is found in a standard place on a printed sheet not in a random spot in illegible notes. A longer questionnaire of the type they describe has been filled in conscientiously by more than $90 \%$ of new patients attending my clinic for the past 12 years. The practioe may be the norm in a few years. A few additional hints may therefore be helpful. (1) The questionnaire should be individualized
to suit the clinician's specialty. My special interests are renal and hepatic diseases, so half my patients are renal and hepatic diseases, so haff my patients
sent by general practitioners have urinary infection or hypertension or both and half the referrals from other consultants are for renal failure. A questionnaire that did not explore these subjects in depth would be of little use to me but the three pages 1 give to renal disease would be excessive for most other clinicians. A personal version is not adminstratively difficult to use. The secretary knows which consultant the patient will see and can readily extract the appropriate version from a few

(2) There should be clear instructions on how to fill in the form-for example, "Please answer the quil in the form-for example, "Please answer the questions by putting a ring round the appropriate answer." A questionnaire with the answers ringed is much easier to read than one with the alternatives deleted. Some questions are better couched in vernacular. A Tynesider instantly recognizes "backbody" and "forebody" as synonyms for anus and vulva.

(3) Positive (that is, pathological) responses should be arranged down the right hand side of the page, with a wide margin for brief comment, like this:

Can you start to pass water without hesitation? Yes No. Do you dribble for a while after stopping?
No Yes.

How often do you rise at night to pass water? Never Occasionally Regularly Twice Thrice

With this arrangement a largely negative questionnaire can be read at a glance.

(4) Family history is difficult to obtain on a each category of relative individually and ask specifically for age, state of health, or cause of eath.

(5) Information about past and present drug therapy is important. Analgesics and oral contraceptives are worthy of specific questions since they are of ten omitted if not spelt out in detail (including common trade names of analgesics). Drug identification at the clinic can be improved by using a sample display, which must be kept in a locked sample display, which must

(6) A modified questionnaire can be used for the repetitive questioning of follow-up, such as in dialysis and transplant review clinics. One has been used at our dialysis follow-up clinic for five years and has proved invaluable in research as well as patient care. It is readily adaptable to computer vative management of chronic renal failure.

(7) It is uneconomic to print individualized questionnaires but cyclostyled versions are acceptable and may be revised in the light of experience. Some questions have to be eliminated because they generate too many positive responses-about half the women in this area claim to be uncomfortable in both hot and cold weather. No rephrasing of these questions eliminated the false-positives answers.-I am, etc.,

Royal Victoria Infirmary,

DAVID KERR Newcastle upon Tyne

\section{Nurses in Administration}

SIR,-For some considerable time members of the medical profession have been using your correspondence coloumns to express their disquiet with the consequences of the Salmon recommendations for nursing staff. I would like now to draw the attention of your readers to an even more pernicious development in nursing care than Salmon. This is the proliferation of administrative nurses which is a consequence of the reorganization of the Health Service and the setting up of the area health authorities.

In the Cleveland A.H.A., where I work, we formerly had three general hospital groups, each of which had been Salmonized with appropriate administrative nurses and, in addition to this, we had two local authority nursing services, each of which had 